\title{
A RATING SCALE FOR DEPRESSION
}

\author{
BY \\ MAX HAMILTON \\ From the Department of Psychiatry, University of Leeds
}

The appearance of yet another rating scale for measuring symptoms of mental disorder may seem unnecessary, since there are so many already in existence and many of them have been extensively used. Unfortunately, it cannot be said that perfection has been achieved, and indeed, there is considerable room for improvement.

\section{Types of Rating Scale}

The value of this one, and its limitations, can best be considered against its background, so it is useful to consider the limitations of the various rating scales extant. They can be classified into four groups, the first of which has been devised for use on normal subjects. Patients suffering from mental disorders score very highly on some of the variables and these high scores serve as a measure of their illness. Such scales can be very useful, but have two defects: many symptoms are not found in normal persons; and less obviously, but more important, there is a qualitative difference between symptoms of mental illness and normal variations of behaviour. The difference between the two is not a philosophical problem but a biological one. There is always a loss of function in illness, with impaired efficiency.

Self-rating scales are popular because they are easy to administer. Aside from the notorious unreliability of self-assessment, such scales are of little use for semiliterate patients and are no use for seriously ill patients who are unable to deal with them.

Many rating scales for behaviour have been devised for assessing the social adjustment of patients and their behaviour in the hospital ward. They are very useful for their purpose but give little or no information about symptoms.

Finally, a number of scales have teen devised specifically for rating symptoms of mental illness. They cover the whole range of symptoms, but such all-inclusiveness has its disadvantages. In the first place, it is extremely difficult to differentiate some symptoms, e.g., apathy, retardation, stupor. These three look alike, but they are quite different and appear in different settings. Other symptoms are difficult to define, except in terms of their settings, e.g., mild agitation and derealization. A more serious difficulty lies in the fallacy of naming. For example, the term "delusions" covers schizophrenic, depressive, hypochrondriacal, and paranoid delusions. They are all quite different and should be clearly distinguished. Another difficulty may be summarized by saying that the weights given to symptoms should not be linear. Thus, in schizophrenia, the amount of anxiety is of no importance, whereas in anxiety states it is fundamental. Again, a schizophrenic patient who has delusions is not necessarily worse than one who has not, but a depressive patient who has, is much worse. Finally, although rating scales are not used for making a diagnosis, they should have some relation to it. Thus the schizophrenic patients should have a high score on schizophrenia and comparatively small scores on other syndromes. In practice, this does not occur.

The present scale has been devised for use only on patients already diagnosed as suffering from affective disorder of depressive type. It is used for quantifying the results of an interview, and its value depends entirely on the skill of the interviewer in eliciting the necessary information. The interviewer may, and should, use all information available to help him with his interview and in making the final assessment. The scale has undergone a number of changes since it was first tried out, and although there is room for further improvement, it will be found efficient and simple in use. It has been found to be of great practical value in assessing results of treatment.

\section{Description of the Rating Scale}

The scale contains 17 variables (see Appendix I). Some are defined in terms of a series of categories of increasing intensity, while others are defined by a number of equal-valued terms (see Appendix II). The form on which ratings are recorded also includes four additional variables: Diurnal variation, derealization, paranoid symptoms, obsessional symp- 
toms. These are excluded from the scale because the first is not a measure of depression or of its intensity, but defines the type of depression. The other three occur so infrequently that there is no point in including them.

The variables are measured either on five-point or three-point scales, the latter being used where quantification of the variable is either difficult or impossible. No distinction is made between intensity and frequency of symptom, the rater having to give due weight to both of them in making his judgment.

Various problems are to be found with specific symptoms. Thus considerable difficulty is found with the depressive triad: depressive mood, guilt, and suicidal tendencies. These are so closely linked in description and judgment as to be very difficult to separate. It is very important to avoid the halo effect by automatically giving all of them high or low scores, as the case may be.

Depressed Mood.-This tends to have a narrow range of scores, for no diagnosed patients will score zero and few will score 1 or 4 . The most useful indicator for depressed mood is the tendency to weep, but it must always be considered against the cultural background, and patients may also "go beyond weeping".

Suicide.-An attempt at suicide scores 4 , but such an attempt may sometimes occur suddenly against a background of very little suicidal tendency; in such cases it should be scored as 3. There will be great difficulty sometimes in differentiating between a real attempt at suicide and a demonstrative attempt; the rater must use his judgment.

Work and Loss of Interest.-Difficulties at work and loss of interest in hobbies and social activities are both included. The patient who has given up work solely because of his illness is rated 4 .

Retardation.-A grade 4 patient is completely mute, and is therefore unsuitable for rating on the scale. Grade 3 patients need much care and patience to rate, but it can be done.

Agitation.-This is defined as restlessness associated with anxiety. Unfortunately, a five-point scale was found impracticable, and therefore this variable is rated on a three-point scale. The mildest degrees of agitation cause considerable difficulty.

Gastro-intestinal Symptoms.- These occur in connexion with both anxiety and depression. Considerable clinical experience is required to evaluate them satisfactorily. The definitions given have been found very useful in practice.

General Somatic Symptoms.-In depressions these are characteristically vague and ill defined, and it is extremely difficult to get a satisfactory description of them from the patient.

Hypochondriasis. - This is easy to rate when it is obviously present, but difficulties arise with mild hypochondriacal preoccupations. Phobias of specific disease can cause difficulties. A phobia of venereal disease or of cancer will sometimes be rated under "guilt" by the nature of the symptom, but other cases may give rise to much doubt and judgment requires care. Fortunately, phobias are not common, but the whole subject of hypochondriasis could well repay clinical investigation.

Insight.-This must always be considered in relation to the patient's thinking and background of knowledge. It is important to distinguish between a patient who has no insight and one who is reluctant to admit that he is "mental".

Loss of Weight.-Ideally this would be measured in pounds or kilograms, but few patients know their normal weight and keep a check on it. It was therefore necessary to use a three-point scale.

After recovery from depression, some patients sometimes show a brief hypomanic reaction, during which the exuberantly cheerful patient will deny that he has any symptoms whatever, though he is obviously not to be regarded as normal. In such cases, the rating scale is inapplicable and should be delayed until the patient has fully recovered.

\section{Scoring}

It is particularly useful to have two raters independently scoring a patient at the same interview, since this gives data for calculating the interphysician reliability. The score for the patient is obtained by summing the scores of the two physicians. This is, of course, the best way of learning how to use the scale, Where only one rater uses the scale, the scores should be doubled so as to make them comparable. With sufficient experience, a skilled rater can learn to give half-points.

\section{Results}

For two raters, the correlation between summed scores for the first 10 patients was 0.84. Adding successively 10 patients at a time, the correlation changed to $0.84,0.88,0.89,0.89,0.90,0.90$. The last correlation is therefore total for 70 patients.

Product-moment correlations were calculated for the 17 variables on the first 49 male patients (Table I). The correlation matrix was then factoranalysed by extracting the latent roots and vectors (Table II). As the intercorrelations are in general low because of the intense selection of patients, the latent roots (variances extracted by factors) diminish 
TABLE I

CORRELATION MATRIX OF THE SCALE FOR DEPRESSION

\begin{tabular}{|c|c|c|c|c|c|c|c|c|c|c|c|c|c|c|c|c|c|c|}
\hline & & (1) & (2) & (3) & (4) & (5) & (6) & (7) & (8) & (9) & (10 & (11) & (12 & (13) & (14 & (15) & (16) & $\bar{\Phi}(1)$ \\
\hline $\begin{array}{r}1 \\
2 \\
3 \\
4 \\
5 \\
6 \\
7 \\
8 \\
9 \\
10 \\
11\end{array}$ & $\begin{array}{l}\text { Depressed mood } \\
\text { Guilt } \\
\text { Suicide } \\
\text { Insomnia, initial } \\
\quad \text { " middle } \\
\text { Work and interests } \\
\text { Work } \\
\text { Retardation } \\
\text { Agitation } \\
\text { Anxiety, psychic } \\
\quad, \quad \text { somatic }\end{array}$ & 1.0 & $\begin{array}{l}0.491 \\
1.0\end{array}$ & $\begin{array}{l}0.373 \\
0.522 \\
1.0\end{array}$ & $\begin{array}{r}0.082 \\
-0.049 \\
0.043 \\
1.0\end{array}$ & \begin{tabular}{r|}
0.236 \\
-0.048 \\
0.098 \\
0.199 \\
1.0
\end{tabular} & \begin{tabular}{|l|}
0.140 \\
0.121 \\
-0.073 \\
0.309 \\
0.054 \\
1.0
\end{tabular} & $\begin{array}{l}0.362 \\
0.358 \\
0.016 \\
0.130 \\
0.035 \\
0.17 \\
1.0\end{array}$ & \begin{tabular}{r|}
0.590 \\
0.370 \\
0.335 \\
-0.115 \\
0.200 \\
0.126 \\
0.230 \\
1.0
\end{tabular} & $\begin{aligned} 0.055 \\
0.027 \\
-0.068 \\
0.191 \\
0.126 \\
0.022 \\
0.183 \\
-0.305 \\
1.0\end{aligned}$ & \begin{tabular}{|c|}
-0.198 \\
-0.167 \\
-0.216 \\
-0.001 \\
0.003 \\
-0.180 \\
0.017 \\
-0.365 \\
0.274 \\
1.0
\end{tabular} & \begin{tabular}{|r|}
-0.224 \\
-0.151 \\
-0.065 \\
-0.036 \\
0.095 \\
-0.162 \\
-0.045 \\
-0.356 \\
0.329 \\
0.370 \\
1.0
\end{tabular} & \begin{tabular}{|r|}
-0.032 \\
0.071 \\
-0.087 \\
0.438 \\
0.308 \\
0.376 \\
0.285 \\
0.067 \\
0.199 \\
-0.146 \\
-0.082 \\
\end{tabular} & $\begin{array}{r}0.014 \\
-0.063 \\
-0.115 \\
0.169 \\
0.278 \\
-0.038 \\
0.094 \\
0.127 \\
-0.107 \\
-0.058 \\
0.060\end{array}$ & \begin{tabular}{|r|}
0.370 \\
0.426 \\
0.304 \\
-0.044 \\
0.111 \\
0.142 \\
-0.058 \\
0.269 \\
0.045 \\
-0.026 \\
0.033
\end{tabular} & $\begin{array}{r}-0.024 \\
0.113 \\
-0.042 \\
0.152 \\
0.067 \\
0.171 \\
-0.020 \\
-0.208 \\
0.001 \\
0.043 \\
-0.014\end{array}$ & $\begin{array}{r}0.341 \\
0.419 \\
0.201 \\
0.179 \\
0.146 \\
0.012 \\
0.313 \\
0.232 \\
0.217 \\
-0.159 \\
-0.310\end{array}$ & 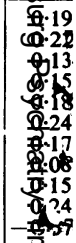 \\
\hline $\begin{array}{l}12 \\
13 \\
14 \\
15 \\
16 \\
17\end{array}$ & $\begin{array}{l}\text { Somatic, gastro- } \\
\text { intestinal } \\
\text { Somatic general } \\
\text { ", genital } \\
\text { Hypochondriasis } \\
\text { Insight } \\
\text { Loss of weight }\end{array}$ & & & & & & & & & & & & & $\begin{array}{l}0.248 \\
1.0\end{array}$ & $\begin{array}{c}-0.115 \\
0.048 \\
1.0\end{array}$ & $\begin{array}{l}0 \cdot 135 \\
0 \cdot 137 \\
0 \cdot 199 \\
1 \cdot 0\end{array}$ & $\begin{array}{r}0.074 \\
-0.024 \\
0.254 \\
0.275 \\
1.0\end{array}$ & 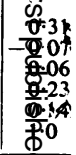 \\
\hline
\end{tabular}

TABLE II

FACTOR SATURATIONS AND LATENT ROOTS

\begin{tabular}{|c|c|c|c|c|c|}
\hline & Condition & Factor 1 & Factor 2 & Factor 3 & Factor 4 \\
\hline $\begin{array}{l}(1) \\
(2) \\
(3) \\
(4) \\
(5) \\
(6) \\
(7) \\
(8) \\
(9) \\
(10) \\
(11) \\
(12)\end{array}$ & $\begin{array}{l}\text { Depressed mood } \\
\text { Guilt } \\
\text { Suicide } \\
\text { Insomnia, initial } \\
\text { middle } \\
\text {," delayed } \\
\text { Work and interests } \\
\text { Retardation } \\
\text { Agitation } \\
\begin{array}{l}\text { Anxiety, psychic } \\
\text {, somatic }\end{array} \\
\text { Somatic, gastro-- } \\
\text { intestinal }\end{array}$ & $\begin{array}{r}0.763 \\
0.728 \\
0.531 \\
0.207 \\
0.284 \\
0.338 \\
0.458 \\
0.683 \\
-0.034 \\
-0.373 \\
-0.403\end{array}$ & $\begin{array}{r}-0.156 \\
-0.311 \\
0.614 \\
0.363 \\
0.371 \\
0.275 \\
-0.371 \\
0.539 \\
0.326 \\
0.250\end{array}$ & $\begin{array}{r}0.103 \\
0.341 \\
0.283 \\
-0.208 \\
-0.081 \\
-0.304 \\
0.043 \\
-0.253 \\
0.503 \\
0.557 \\
0.480\end{array}$ & $\begin{array}{r}0.151 \\
-0.138 \\
0.122 \\
-0.025 \\
0.639 \\
-0.340 \\
-0.134 \\
0.224 \\
-0.032 \\
0.072 \\
0.421\end{array}$ \\
\hline $\begin{array}{l}(12) \\
(13) \\
(14) \\
(16) \\
(17)\end{array}$ & $\begin{array}{l}\text { Gomatic, gastro- } \\
\text { intestinal } \\
\text { general } \\
\text { Genital } \\
\text { Hypochondriasis } \\
\text { Insight } \\
\text { Loss of weight }\end{array}$ & $\begin{array}{l}0.282 \\
0.087 \\
0.474 \\
0.157 \\
0.603 \\
0.353\end{array}$ & $\begin{array}{r}0.674 \\
0.245 \\
-0.139 \\
0.367 \\
0.107 \\
0.439\end{array}$ & $\begin{array}{r}-0.395 \\
-0.356 \\
0.397 \\
0 \cdot 117 \\
0 \cdot 204 \\
0.214\end{array}$ & $\begin{array}{r}-0.010 \\
0.628 \\
0.225 \\
-0.144 \\
-0.173 \\
-0.192\end{array}$ \\
\hline & Latent root & 3.4358 & $2 \cdot 3439$ & 1.7496 & $1 \cdot 365$ \\
\hline
\end{tabular}

slowly. Out of the total variance of 17 , the first six roots take up $3.44,2.34,1.75,1.37,1.28,1.07,0.99$. The first four factors were used for calculating factor measurements for the patients, in the form of T-scores.

For the interest of those factorists who have a taste for factors rotated to give simple structure, the first three factors were rotated by an orthogonal rotation matrix (Table III) to give the results shown in Table IV. The fourth factor was left as it is, as it already has a fair number of near-zero saturations. The final saturations give a good approximation to simple structure and still retain the advantage of orthogonality.

TABLE III

ORTHOGONAL ROTATION MATRIX

\begin{tabular}{|c|c|c|c|}
\hline Factor & & Matrix & \\
\hline $\begin{array}{l}\mathbf{F}_{1} \\
\mathbf{F}_{2} \\
\mathbf{F}_{3}\end{array}$ & $\begin{array}{r}0.7377 \\
-0.4182 \\
0.5300\end{array}$ & $\begin{array}{l}0.4932 \\
0.8699 \\
0\end{array}$ & $\begin{array}{r}-0.4610 \\
0.2614 \\
0.8480\end{array}$ \\
\hline
\end{tabular}

TABLE IV

SATURATIONS OF ROTATED FACTORS

\begin{tabular}{|c|c|c|c|c|c|}
\hline & Condition & Factor 1 & Factor 2 & Factor 3 & Factor 4 \\
\hline (3) & Suicide & 0.672 & -0.009 & -0.086 & $0 \cdot 122$ \\
\hline (14) & Genital & 0.618 & $0 \cdot 113$ & 0.081 & 0.225 \\
\hline (2) & Guilt & 0.783 & $0 \cdot 224$ & -0.087 & $-0 \cdot 138$ \\
\hline (8) & Retardation & 0.525 & 0.014 & -0.620 & $0 \cdot 224$ \\
\hline (1) & Depressed mood & 0.690 & 0.227 & -0.309 & $0 \cdot 151$ \\
\hline (12) & 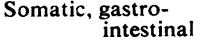 & $-0 \cdot 283$ & 0.725 & $-0 \cdot 288$ & -0.010 \\
\hline (16) & Loss of insight & 0.508 & 0.401 & $\overline{-0.077}$ & $-0 \cdot 173$ \\
\hline (4) & Insomnia, initial & -0.214 & 0.637 & -0.111 & -0.025 \\
\hline (5) & middle & 0.015 & 0.456 & $-0 \cdot 105$ & 0.639 \\
\hline (7) & Work and interests & $0 \cdot 245$ & 0.466 & $-0 \cdot 102$ & -0.134 \\
\hline (15) & Hypochondriasis & 0.024 & 0.397 & $0 \cdot 123$ & $-0 \cdot 144$ \\
\hline (17) & Loss of weight & $0 \cdot 190$ & 0.556 & 0.133 & $-0 \cdot 192$ \\
\hline (6) & Insomnia, delayed & -0.067 & 0.490 & -0.311 & $-0.341)$ \\
\hline (9) & Agitation & 0.016 & 0.453 & 0.583 & $-0 \cdot 032$ \\
\hline (10) & Anxiety, psychic & -0.117 & $0 \cdot 100$ & 0.730 & 0.072 \\
\hline (11) & ,, somatic & $-0 \cdot 148$ & -0.019 & 0.658 & 0.421 \\
\hline (13) & Somatic, general & $-0 \cdot 227$ & $0 \cdot 256$ & -0.278 & 0.628 \\
\hline
\end{tabular}

Factor Saturations.-It is customary to examine the factor saturations in order to give an appropriate name to the factors. When all the variables are positively correlated, the general factor may be regarded as an overall average of the items; but when, as in this case, a group of the variables is negatively correlated with the rest, this notion of an average becomes a little tenuous. Be that as it may, there would be little objection to the proposal to call the first factor "retarded depression" on the basis of its factor saturations. The important ones are, in descending order, depressed mood 0.76 , guilt 0.73 , retardation $0 \cdot 68$, loss of insight $0 \cdot 60$, suicide $0 \cdot 53$, genital symptoms (loss of libido) $0 \cdot 47$, work and interest 0.46 , anxiety (somatic) 0.40 , anxiety (psychic) 0.37 , loss of weight 0.35 , and insomnia (delayed) $0 \cdot 34$. The correspondence with the classical descriptions is remarkably close. The saturations in the second factor are: Somatic symptoms (gastro-intestinal) $\mathbf{0 \cdot 6 7}$, insomnia (initial) 0.61 , 
agitation 0.54 , loss of weight 0.44 , retardation 0.37 , insomnia (delayed) 0.37 , insomnia (middle) 0.36 , hypochondriasis 0.37 , anxiety (psychic) 0.33 , and suicide 0.31 . It might be said to be vaguely like agitated depression, which clinically shows anxiety and agitation, together with disturbed sleep (particularly initial insomnia), but the factor is deficient in depression, the first factor having taken out most of the depressive variance. The third factor might be called some sort of anxiety reaction, with saturations of anxiety (psychic) $0 \cdot 56$, agitation $0 \cdot 50$, anxiety (somatic) 0.50 , genital (loss of libido) symptoms $0 \cdot 40$, gastrointestinal symptoms -0.39 , general somatic symptoms $-0 \cdot 36$, guilt $0 \cdot 34$, and insomnia (delayed) $-0 \cdot 30$. The fourth factor has saturations of insomnia (middle) 0.64 , general somatic symptoms 0.63 , anxiety (somatic) 0.42 , and insomnia (delayed) $-0 \cdot 34$. It is difficult to attach any label to the third and fourth factors, as they do not bring any clinical pattern to mind.

The situation is no better with the rotated factors. Factor $I$ is still very much like retarded depression, but the negative saturation for gastrointestinal symptoms strikes a most incongruous note. Fastor II shows many somatic symptoms and disturbed sleep, but the presence in the factor of agitation without anxiety is disturbing. It cannot be regarded as a factor of objective symptoms, as opposed to subjective, since it includes loss of interest and insight. Factor III could be named "anxiety reaction", but the negative saturations of depression and loss of insight must disqualify any attempt to relate it to clinical syndromes. The fourth factor has been left unrotated.

It is not surprising that the classical clinical syndromes have not appeared from the factor analysis, since this technique is incapable of demonstrating them. It would appear from the literature that psychologists have hoped that factor analysis would elicit the classical syndromes, and perhaps even additional ones, but in practice this does not occur. The clinical syndromes are mutually exclusive, i.e., a patient can be ill with endogenous depression, or reactive depression, or schizophrenia, etc., but not from two or more. Of course, there are always patients who diagnostically are doubtful in-betweens. On the other hand, factors are orthogonal, and any individual patient can have high scores in two or more factors, or conversely, low scores. The discrepancy between clinical syndromes and factors is even greater when correlated factors are obtained by non-orthogonal rotations, for with such factors, patients will tend to score high or low in all factors simultaneously.

The appropriate statistical technique for describing the clinical syndromes in terms of quantified variables is that of discriminant functions. These divide the multidimensional space into regions, the centres of which characterize the typical case, and the meeting of the regions, the "interfaces", are the sites where are located the atypical, anomalous, or half-way cases. Since this procedure requires the initial establishment of criterion groups, already diagnosed, it cannot therefore be used to find syndromes. It can be used to test the (null) hypothesis that the syndromes are not distinct, and to identify new cases.

\section{Factor Measurements}

Another way of investigating the nature of the factors is to consider the individuals who have high scores on the factors:-

Factor 1.-A man aged 39 years (Case 39) had factor scores of $F_{1} 76, F_{2} 37, F_{3} 49$, and $F_{4} 52$.

This patient was admitted to hospital after two attempts at suicide, first by electrozution, and, when this failed, by an overdose of phenobarbitone. No psychological precipitating factors were found. On admission he was severely depressed and still actively suicidal. $\mathrm{He}$ had strong feelings of guilt, and feared that he had acquired venereal disease and was infecting others with it. He was markedly retarded and showed loss of insight. His sleep was disturbed in all three phases, he had no interest in anything and had complete loss of libido since the onset of his illness four months previously. His symptoms cleared with six courses of electroshock treatment (E.C.T.). Two weeks later he suddenly relapsed and attempted to cut his wrists with a broken tumbler. He again recovered with a further course of E.C.T. and has remained well ever since.

This case was one of classical endogenous depression.

Case 24.-A man aged 54 had factor scores of $F_{1} 64$, $\mathrm{F}_{2} 51, \mathrm{~F}_{3} 44$, and $\mathrm{F}_{4} 50$.

This patient developed symptoms of anxiety two years ago, accompanied by impotence. As a result of physical illness, he had to change his job to one much less satisfactory and with less pay. He worried excessively over this and over his health, and became very depressed. He was given E.C.T. as an out-patient, improved and returned to work for three months. $\mathrm{He}$ was twice admitted to hospital, refused E.C.T., and discharged himself. Eventually he agreed to accept E.C.T. but committed suicide just before he was due to attend for treatment. When in hospital he was deeply depressed, had some guilt feelings, suicidal thoughts, and moderate retardation. He had difficulty in falling asleep and woke in the early hours. He showed loss of interest and of libido. He lacked insight, had lost weight, and complained of vague bodily symptoms. He showed little anxiety but was preoccupied with his health and his future prospects.

Psychological precipitating factors cannot be excluded. but the overall picture is that of endogenous depression.

Factor 2.-A man aged 62 years (Case 61) had factor scores of $F_{1} 32, F_{2} 54, F_{3} 37$, and $F_{1} 38$. 
This patient had been off work for 11 years for "bad nerves" following an accident at work. He had many hypochondriacal complaints and had undergone many fruitless investigations. Four years ago, he was admitted to hospital for severe depression with delusions and hallucinations. This cleared after E.C.T. He was readmitted a year ago, diagnosed as a case of reactive depression, and improved slowly under general treatment. He was discharged after three months. His condition fluctuated and eventually he was readmitted, given six courses of E.C.T. and showed marked improvement. He was discharged and remained well. His symptoms were of moderate depression, without feelings of guilt or suicidal ideas. He had difficulty in falling asleep and awoke early. He showed moderate loss of interest, anxiety, both psychic and somatic, and suffered from poor appetite and constipation. He was diagnosed as a case of reactive depression, but the relation of the illness to psychological precipitating factors is not certain.

Case 17.-A man aged 72 years had factor scores of $F_{1} 48, F_{2} 65, F_{3} 43$, and $F_{4} 45$.

There was a long history of abdominal complaints, but investigations found nothing to account for them. A year ago the patient became obviously depressed and was admitted to hospital. He showed moderate depression, guilt, and some suicidal preoccupations. His sleep was disturbed in all three phases. He showed loss of interest, some agitation, severe hypochondriasis, and considerable anxiety. His appetite was poor, his bowels were constipated, and he had lost weight. Because of the poor state of his heart, he was not given E.C.T. He improved slowly, finally discharging himself against advice. Eventually he was admitted to a general hospital and died from cancer of the lung.

The clinical picture is that of reactive depression, but the psychological precipitating factors are doubtful.

Factor 3.-A man aged 61 years (Case 2) had factor scores of $F_{1} 41, F_{2} 38, F_{3} 63$, and $F_{4} 44$.

The patient had a history of several attacks of depression, the last one precipitated by the deaths of his wife and daughter. The course of the illness was fluctuating, and the patient showed a poor response to E.C.T. He showed marked depression, guilt, suicidal thinking, retardation, loss of interest, and grossly disturbed sleep. Eventually he recovered and has remained well.

Case 45.-A man aged 53 years had factor scores of $F_{1} 60, F_{2} 55, F_{3} 78$, and $F_{4} 52$.

The patient had had one previous attack of depression four years before. Two years ago, the patient again fell ill, and his symptoms have fluctuated considerably. In hospital he showed much depression, guilt, and loss of interest, much anxiety and agitation, loss of libido and loss of insight. $\mathrm{He}$ is a rather inadequate personality and his present illness began when he was offered a post which involved greater responsibility.

Both of these patients have had previous attacks of depression, characteristic of an endogenous type of disorder, but in both cases, there were obvious psychological stresses to account for the onset of the present attack. In the first, the symptoms were of the endogenous (retarded) type, and in the second of the reactive (agitated) type. Clinically, these patients are very unlike, but the factor scores pick them out on account of their resemblance; what this is, is not clear.

Since the factors are derived from a limited number of cases, the fourth factor is of very doubtful stability. (The question of statistical significance is ignored for the moment.) Nevertheless, it is of considerable interest. Both of the following patients showed depression with much anxiety, disturbance of sleep and many somatic symptoms, but it is the background to the illness that is noteworthy.

Factor 4.-A man aged 51 years (Case 62) had factor scores of $F_{1} 39, F_{2} 41, F_{3} 56$, and $F_{4} 71$.

This patient was a hard worker, but could not restrain his heavy drinking and gambled heavily. These caused considerable marital discord. When temporarily out of work after an accident, he stole money from his daughter to continue his "hobbies". He went off to London, stayed in a hotel and decamped without paying. When he eventually returned home, he heard that the theft had been reported to the police. He became desperate, and after a few days attempted to gas himself and was admitted to hospital. His condition cleared after E.C.T.

Case 7.-A man aged 44 years had factor scores of $F_{1} 34, F_{2} 44, F_{3} 58$, and $F_{4} 71$.

This patient came from a disturbed parental home where he had been rejected and deprived. He has always been an odd personality with marked neurotic traits and paranoid attitudes. He served in the Royal Air Force for nine years, during which he was repeatedly delinquent and resistant to authority. Eventually he was discharged for "psychoneurosis". His subsequent occupational history is irregular, with frequent loss of jobs because of quarrelling. He always feels that others are against him. He has not worked for years, has shown much anxiety and in the last six months became depressed, being finally admitted to hospital. He improved a little after E.C.T. but relapsed, subsequently recovering spontaneously.

Both of these patients have obviously abnormal personalities, although it would be an exaggeration to describe them as psychopathic personalities. It has long been recognized that abnormal personalities, particularly of the hysterical type, are liable to attacks of depression, and it is of great interest that such patients should be picked out by reason of the pattern of symptoms of their depression. Nevertheless, the present findings should not be regarded as more than suggestive and worthy of further investigation.

Another way of tackling the relation between factors and clinical syndromes is to take groups of clinically identified patients and compare their mean 
factor measurements. Since this is purely a clinical problem and involves other matters, it is reported elsewhere (Hamilton and White, 1959).

Tests of significance have not been applied to these factors. It seems likely that even the smallest factor would become statistically significant if a sufficient number of patients were tested, and the ratings were repeated often enough to make the individual variables highly reliable. The value of factors lies in their use. In this connexion, although the data for the factor analysis were derived from 49 patients, the regression equations were used on the ratings obtained from 64 patients investigated for other purposes. Of these 64 patients, 49 were followed up after treatment (not the same 49). The correlation between factor measurements and total crude score after treatment is for $F_{1} \mathbf{0} \cdot 23$, for $F_{2} 0 \cdot 17$, for $F_{3} 0 \cdot 27$, and for $F_{4}-0 \cdot 09$. Although $F_{3}$ has no obvious clinical or psychological meaning, it is the only one of the factors to be correlated with outcome after treatment at a significance level of just over $5 \%$. This is not much, but a large correlation with outcome is not to be expected in such a highly selected group of patients (Hamilton and White, 1959). Furthermore, 16 out of the 49 cases followed up are new cases, so that some of the shrinkage to be expected in a cross-validation group has already occurred. (The situation is not quite the same as when a multiple correlation is calculated, but $F_{3}$ has been picked out because it has the highest correla- tion with outcome. Herein lies the interest of this factor.)

\section{Summary}

A rating scale is described for use in assessing the symptoms of patients diagnosed as suffering from depressive states. The first four latent vectors of the intercorrelation matrix obtained from 49 male patients are of interest, as shown by $(a)$ the factor saturations, $(b)$ the case histories of patients scoring highly in the factors, and $(c)$ the correlation between factor scores and outcome after treatment. The general problem of the relationship between clinical syndromes and factors extracted from the intercorrelations of symptoms is discussed.

Thanks are due to Dr. P. F. Fletcher, PhysicianSuperintendent of Stanley Royd Hospital, Wakefield, for giving me full facilities to work in his hospital, and to him and Professor G. R. Hargreaves, of the Department of Psychiatry, Leeds University, for permission to publish. I have to thank Dr. J. White, not only for providing the patients, but also for collaborating in the assessments to give data on reliability. I am indebted to Miss W. Ashton, B.A., B.Sc., of the Computing Laboratory of Leeds University, for the programming of the correlation matrix, latent roots and vectors, and factor measurements. The research fellowship is in part supported by the Mental Health Research Fund.

\section{REFERENCES}

Hamilton, M., and White, J. (1959). J. ment. Sci., 105, 955. Hamilton, M., and White, Unplished data.

A P P E N D I X I

ASSESSMENT OF DEPRESSION

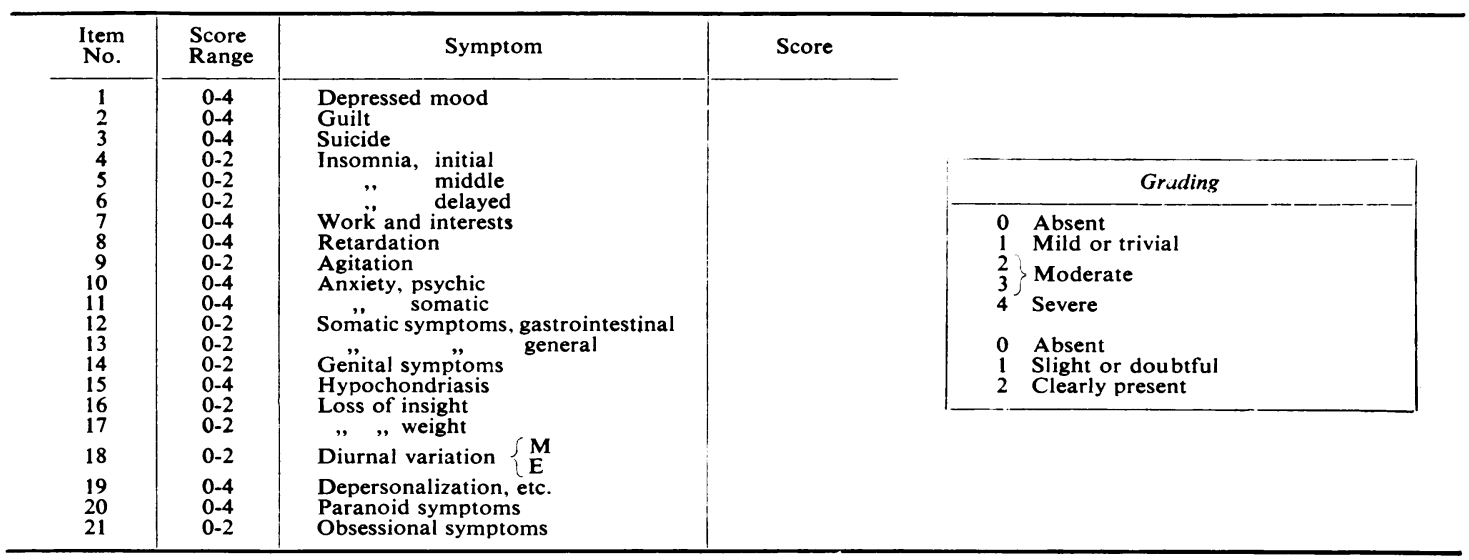


A P P E N D I X I I

CHECK LIST OF SYMPTOMS OF DEPRESSIVE STATES

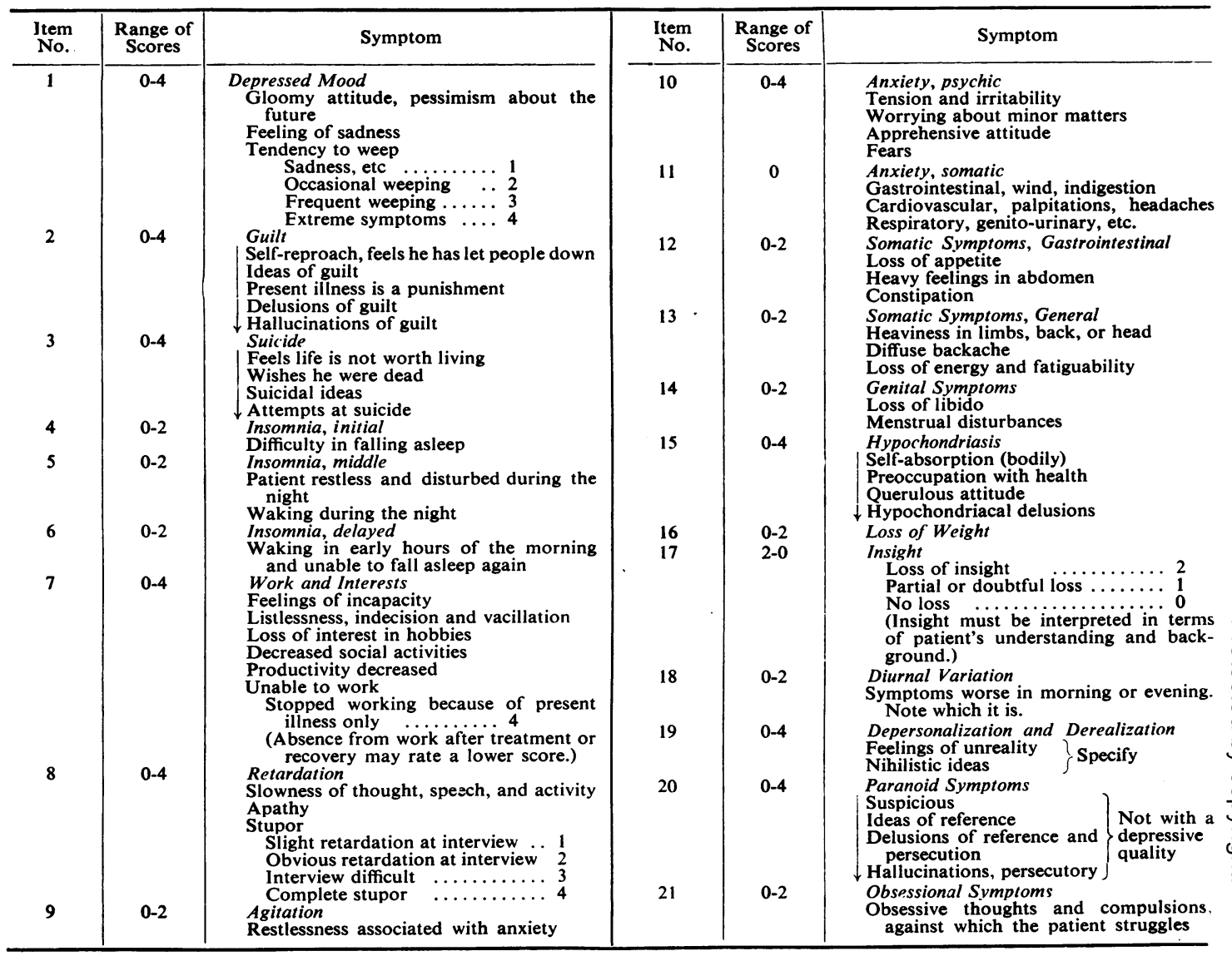

